\title{
COVID-19-related research in Africa: a cross- sectional review of the International Clinical Trial Registration Platform (ICTRP)
}

\author{
Bassey Edem ${ }^{{ }^{*}+} \mathbb{D}$, Victor Williams ${ }^{2 \dagger}$, Chukwuemeka Onwuchekwa ${ }^{3}$, Ama Umesi ${ }^{1}$ and Marianne Calnan ${ }^{4}$
}

\begin{abstract}
Objective: The declaration of the coronavirus disease (COVID-19), a pandemic in early 2020, has seen an upsurge in research globally to fill gaps in the epidemiology of the SARS-CoV-2 virus impact on health care and clinical management, as well as possible prevention and treatment modalities. Published literature on the different types of COVID-19 research conducted globally is varied and is particularly limited in Africa. This study sets out to describe the COVID-19-related research registered and conducted on the African continent.

Methods: This is a cross-sectional study of all COVID-19-related studies available in the WHO's International Clinical Trials Registry Platform (ICTRP) repository. We extracted studies registered from March 1, 2020, to July 15, 2021. A descriptive analysis of the extracted data was performed, and the findings were presented.

Results: At extraction, a total of 12,533 COVID-19-related studies were listed on the ICTRP portal. We included 9803 studies, after excluding 2060 duplicate records and 686 records without a site/country. While 9347 studies (96\%) were conducted outside of Africa, only 456 studies (4\%) were conducted in the African continent, of which 270 (59.2\%) were interventional studies, and 184 (40.4\%) were observational studies. About $80 \%$ of the studies were conducted in Egypt and South Africa, and most of these involved testing of drugs and biologicals.

Conclusion: The African continent hosts considerably fewer COVID-19-related research compared to other parts of the world. This may have implications on scientific evidence available for implementing COVID-19 control efforts. There is, therefore, a need for local funding and ownership of research projects and north-south collaboration in research.
\end{abstract}

\section{Background}

The World Health Organization's declaration of the severe acute respiratory syndrome coronavirus-2 (SARSCoV-2)-related COVID-19 as a pandemic in March 2020 , resulted in the imposition of various restrictions globally, leading to a "shut down" of social and economic activities [1]. Consequently, several studies have been implemented globally to fill the knowledge gap on the

\footnotetext{
* Correspondence: basseyeedem@gmail.com

${ }^{\dagger}$ Bassey Edem and Victor Williams are co-first authors of the study.

'Vaccines and Immunity Theme, MRC Unit the Gambia at the London School of Hygiene and Tropical Medicine, Fajara, Gambia

Full list of author information is available at the end of the article
}

epidemiology of this novel disease and develop and test safe and efficacious interventions such as vaccines and drugs. Indeed, this period has witnessed the most rapid implementation of studies on a public health condition, coupled with the equally rapid dissemination of evidence. The Cochrane group currently hosts a living systematic review of COVID-19 interventions with 3312 clinical trials on record as of August 14, 2021 (https:// covid-nma.com/). Most reported clinical trials on COVID-19 are conducted in the USA, Europe, and China [2-4].

With the rapid turn-over of evidence on COVID-19, it has become progressively more challenging to keep track

(C) The Author(s). 2021 Open Access This article is licensed under a Creative Commons Attribution 4.0 International License, which permits use, sharing, adaptation, distribution and reproduction in any medium or format, as long as you give appropriate credit to the original author(s) and the source, provide a link to the Creative Commons licence, and indicate if changes were made. The images or other third party material in this article are included in the article's Creative Commons licence, unless indicated otherwise in a credit line to the material. If material is not included in the article's Creative Commons licence and your intended use is not permitted by statutory regulation or exceeds the permitted use, you will need to obtain permission directly from the copyright holder. To view a copy of this licence, visit http://creativecommons.org/licenses/by/4.0/. The Creative Commons Public Domain Dedication waiver (http://creativecommons.org/publicdomain/zero/1.0/) applies to the data made available in this article, unless otherwise stated in a credit line to the data. 
of what can only be described as a very "fluid" research landscape. It is vital to have an overarching view of what is being researched and on whom these studies are conducted. For Africa, a region that historically hosts the least clinical trials $[5,6]$, this is of particular importance in ensuring equity in the distribution of the COVID-19 research burden and access to interventions for the control and prevention of the pandemic.

Although only randomized trials require registration as per the International Committee of Medical Journal Editors (ICMJE) and WHO requirements $[7,8]$ to enhance transparency and minimize publication bias in clinical trials, there has been a call for the registration of observational studies for similar reasons $[9,10]$, and indeed, some observational studies are routinely registered in registers such as the ClinicalTrials.gov, albeit in numbers lower than randomized trials [11]. There is limited literature on the types of COVID-19 studies conducted in Africa. In this paper, we describe the characteristics of different registered COVID-19-related studies listed in the International Clinical Trials Registry Platform (ICTR P) that are ongoing in Africa.

\section{Methods}

This research is a cross-sectional study of all COVID-19 studies in the WHO's International Clinical Trial Registration Platform (ICTRP) International Clinical Trials Registry Platform (ICTRP) (who. int). The WHO provides a regularly updated repository of all COVID-19 studies registered in its network of partner registers.

The WHO's clinical trials registry network was established in 2006 and comprised partner regional, or national clinical trial registers that upload information on the studies they hold at defined intervals. The portal provides a single, publicly accessible repository of clinical trials conducted globally. The WHO provides a separate, curated summary of global COVID-19 studies provided by partner registers in its network. We accessed the ICTRP on July 28, 2021, and extracted a listing of all COVID-19-related studies registered in the ICTRP from March 1, 2020, to the last update done on July 15, 2021, for analysis. We chose March 2020 as this was when COVID-19 was declared a pandemic, and countries were implementing various measures to adapt to the pandemic.

\section{Study variables}

The register included forty variables that described the studies listed. After a thorough review, the study team selected eighteen variables aligned with the study's intended inclusion objectives. The first key variable was the study's location as we sought to describe COVID19-related research in Africa. Other vital variables included those that enabled unique identification of each study in the register, study title/objectives, study design, sample size, and target population. Additional variables were the study sponsor, recruitment status, phase of the study, the condition being investigated/specific intervention, the primary outcome, and results were available. The list of variables included in the study is outlined in Fig. 1.

\section{Definitions}

The source register was defined as the primary register the research was documented before uploading to ICTR $\mathrm{P}$. The different registers are defined in Table 1.th $=\mathrm{tl}=$

\section{Data management}

Data were extracted in .xls format and imported into Stata 15 (Stata Corp, College Station TX) for different data management procedures and descriptive analysis. Each study in the ICTRP portal had a unique code assigned to it by the original clinical trial register when the study was first registered. With this unique code as a unique identifier for each study, we used Stata to identify the duplicate studies. The duplicate studies identified were further examined manually to ensure other study parameters such as the date and time of upload, the study title, and the location the studies were conducted were the same before the duplicates were dropped. Studies without a country or location they were conducted were excluded.

A Stata code was used to extract and assign countries in a predefined continent to enable further description and analysis. Variables in the dataset such as country, study design, and type of intervention were entered as free text. These were extracted, manually examined, and categorized before analysis. For missing observations, casewise deletion was employed, and the data was presented.

\section{Data analysis}

A descriptive method was adopted for this study using tables and figures to present findings from the analysis. Categorical variables were described using proportions, while the median (IQR) was used to describe continuous variables. If a particular variable was presented in a qualitative format, similar responses were grouped where possible and presented as proportions. We noted that there were single and multi-country studies. A code was used to identify any study which had an African country as either the only country or one of the countries in the study was being conducted. This enabled the identification of studies that had an African country as a study site in multi-country studies. These were sorted, and the frequency of each African country was identified. African countries with the highest frequencies were presented. Descriptive characteristics of studies within the 


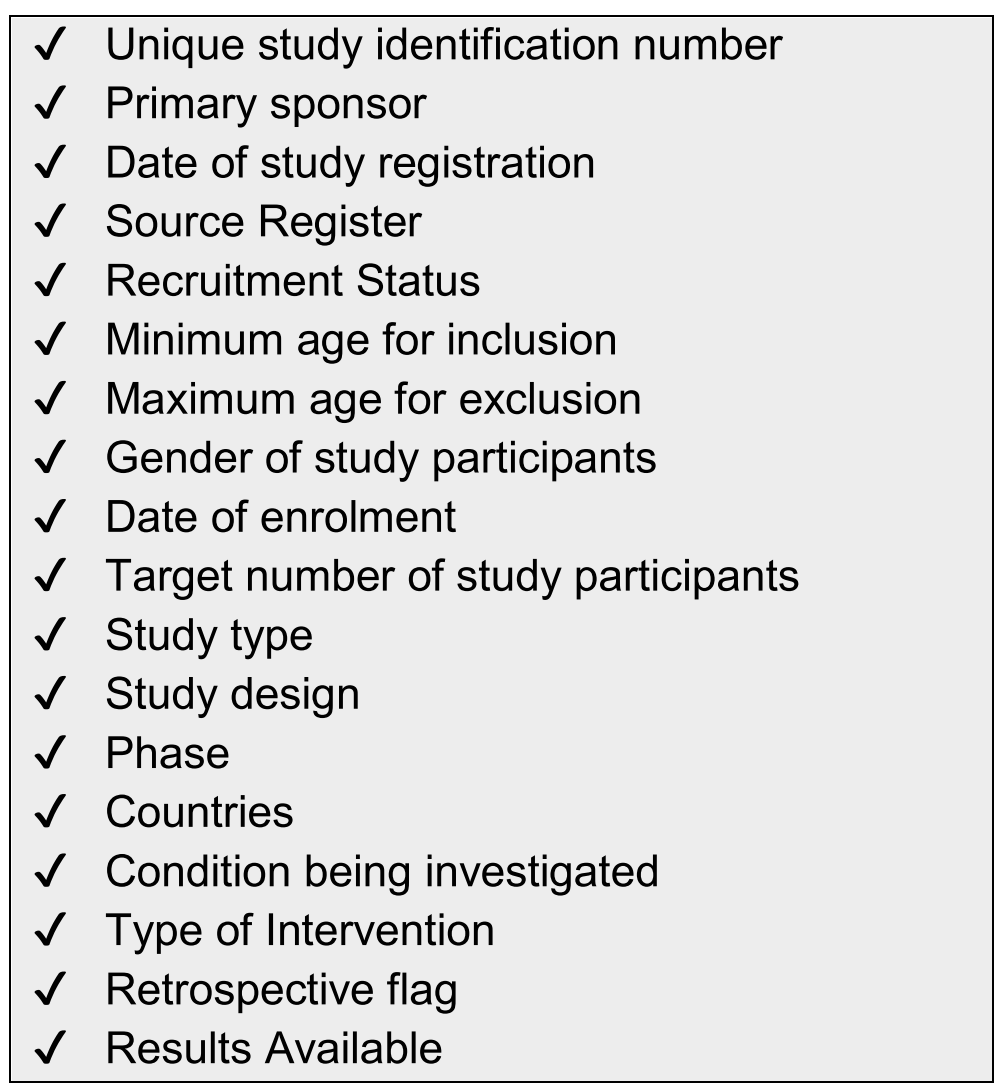

Fig. 1 List of variables included in the study

register are summarized and shown in a table. Three figures describe and compare identified study characteristics.

\section{Results}

We identified 12,533 COVID-19-related studies in the register and included 9803 studies with complete information on the country in our analysis. During data cleaning, some [12] studies which had study sites in Africa were lost during the deduplication process. These were identified and included in the final dataset of studies conducted in Africa. Of the included studies, 456 (4.7\%) were conducted in Africa (Fig. 2a, b). Most of the studies were conducted in Asia (3794 or 38.7\%) and

Table 1 Registers listed in the study

\begin{tabular}{ll}
\hline Register & Full name \\
\hline ANZCTR & Australia New Zealand Clinical Trials Registry \\
CTRI & Clinical Trials Registry-India \\
ChiCTR & Chinese Clinical Trial Register \\
ClinicalTrials.gov & ClinicalTrials.gov \\
EU Clinical Trials Register & European Union Clinical Trials Register \\
GermanCTR & German Clinical Trials Register \\
ISRCTN & International Standard Randomised Controlled Trials Number \\
JPRN & Japan Primary Registries Network \\
PACTR & Pan African Clinical Trials Registry \\
RePEC & Research Papers in Economics \\
TCTR & Thai Clinical Trials Registry \\
\hline
\end{tabular}


Table $\mathbf{2}$ Characteristics of studies conducted in Africa

\begin{tabular}{|c|c|}
\hline Variable description & $(N=456)$ \\
\hline \multicolumn{2}{|l|}{ Target size } \\
\hline Mean (SD) & $6119(36536)$ \\
\hline Median (Q1, Q3) & $264(100,1000)$ \\
\hline \multicolumn{2}{|l|}{ Source register } \\
\hline ANZCTR & $4(0.9 \%)$ \\
\hline CTRI & $15(3.3 \%)$ \\
\hline ChiCTR & $2(0.4 \%)$ \\
\hline ClinicalTrials.gov & $326(71.5 \%)$ \\
\hline EU Clinical Trials Register & $22(4.8 \%)$ \\
\hline German Clinical Trials Register & $3(0.7 \%)$ \\
\hline ISRCTN & $18(3.9 \%)$ \\
\hline JPRN & $5(1.1 \%)$ \\
\hline PACTR & $53(11.6 \%)$ \\
\hline REPEC & $7(1.5 \%)$ \\
\hline TCTR & $1(0.2 \%)$ \\
\hline \multicolumn{2}{|l|}{ Recruitment status } \\
\hline Authorized & $20(4.4 \%)$ \\
\hline Not recruiting & $214(46.9 \%)$ \\
\hline Recruiting & $222(48.7 \%)$ \\
\hline \multicolumn{2}{|l|}{ Study type } \\
\hline Expanded access & $2(0.4 \%)$ \\
\hline Interventional study & $270(59.2 \%)$ \\
\hline Observational study & $184(40.4 \%)$ \\
\hline \multicolumn{2}{|l|}{ Study design } \\
\hline Randomized & $237(52.0 \%)$ \\
\hline Non-randomized & $21(4.6 \%)$ \\
\hline Single group interventional study & $12(2.6 \%)$ \\
\hline Blank & $166(36.4 \%)$ \\
\hline Other & $20(4.4 \%)$ \\
\hline \multicolumn{2}{|l|}{ Phase } \\
\hline N/A & $82(28.0 \%)$ \\
\hline Phase 0 & $1(0.3 \%)$ \\
\hline Phase 1 & $30(10.2 \%)$ \\
\hline Phase 1/phase 2 & $5(1.7 \%)$ \\
\hline Phase 2 & $40(13.7 \%)$ \\
\hline Phase 2/phase 3 & $27(9.2 \%)$ \\
\hline Phase 3 & 89 (30.4\%) \\
\hline Phase 4 & 19 (6.5\%) \\
\hline \multicolumn{2}{|l|}{ Retrospective flag } \\
\hline No & $76(16.7 \%)$ \\
\hline Yes & $380(83.3 \%)$ \\
\hline \multicolumn{2}{|l|}{ Sponsor } \\
\hline Other research/industry & $202(44.3 \%)$ \\
\hline University & $254(55.7 \%)$ \\
\hline
\end{tabular}

Europe (3681 or 37.5\%). North and South America had 2275 registered studies (23.2\%), and Australia/New Zealand had 207 studies (2.1\%). However, 686 studies did not have countries or study locations indicated, 2060 studies were duplicate records, and these were excluded from further analysis (Fig. 2a).

The descriptive characteristics of the studies conducted in Africa are presented in Fig. 3 and Table 2. The African countries with the highest number of registered studies are shown in Fig. 3.

Just more than half of the studies in Africa (232, representing 51.0\%) were conducted in Egypt, followed by South Africa with 101 registered studies (24.1\%). ClinicalTrials.gov was the commonest source register where studies were registered (71.5\%), and most of the studies $(59.2 \%)$ were interventional studies, with $184 \mathrm{ob}-$ servational studies (40.4\%). The interventional studies included 237 randomized controlled trials, 21 nonrandomized studies, and 12 single-group intervention studies. Most studies in Africa (55.7\%) were sponsored by a university or a research institution affiliated with an academic institution.

\section{Types of COVID-19 research in Africa}

Three hundred eighty-three studies out of 456 in Africa had interventions documented (either interventional or observational design). Drug-related research was the most common type of research being conducted in Africa (46.6\%) followed by studies on biological interventions (14.9\%) and diagnostic tests (6.8\%) (Fig. 4). Sub-analysis indicated the drugs being researched were predominantly the antimalarial medication hydroxychloroquine and its variants, Arthemeter, Artesunate, Paracetamol, Colchicine, Lopinavir/Ritonavir, and Atazanavir/Ritonavir. Biological interventions included the use of convalescent plasma or inducing the immune system using a vaccine-chadox, rabies, measles, mumps and rubella (MMR) vaccine, or low dose radiotherapy. We also included 79 studies where the intervention could not be clearly classified into one of the categories.

A sub-analysis of diagnostic test-related research included the use of tuberculin tests, whole-exome sequencing, real-time PCR, serological test, flow cytometry, and semen analysis. Interventions include studies that looked at the usual standard of care received by patients, enhanced care, and introduction of a new intervention to assess patient outcome. Further analysis of "Other" types of COVID-19 research indicates these were Pittsburgh Sleep Quality Index (PSQI) 1 (1\%), usual care 1 (1\%), prevention study 4 (5\%), experimental study 5 (7\%), training 5 [7], survey $21(28 \%)$, and observational study $38(51 \%)$. 


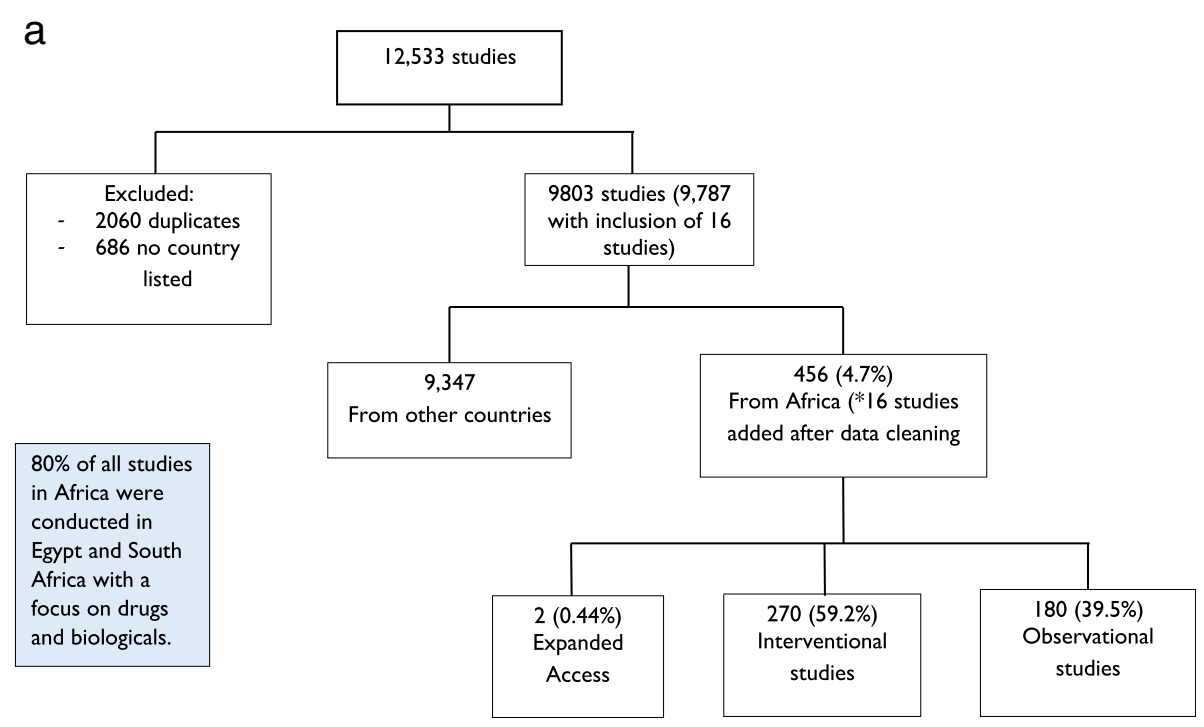

b

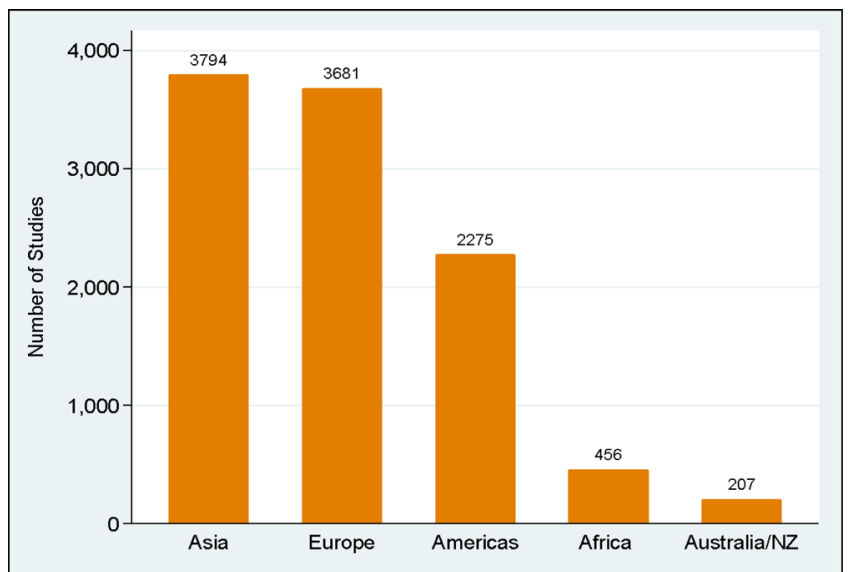

Fig. 2 a Flowchart of studies. *16 studies added after data cleaning. See the "Results" section above for details. b Number of ongoing studies by continent

\section{Discussion}

We set out to describe the types of COVID-19 research conducted in Africa using data in the WHO's International Clinical Trials Registry Platform (ICTRP) portal in this paper. The research priority areas have been identified by the World Health Organization (WHO) and include epidemiological studies of the virus to candidate vaccines research and development (R\&D) [13]. Our results show that all forms of research on COVID-19 are being conducted in Africa. However, Africa hosts fewer COVID-19 trials than other regions, particularly in its size and population. This finding is consistent with data from the COVID-19 research funding tracker, which shows that of the 12,417 plus funded COVID-19 research projects, only
$620(4.9 \%)$ are conducted in Africa [14] and despite that, the location of $3 \%$ of these studies is unknown, this underscores the problem of minimal COVID-19 research in the continent.

There is considerable geographical disparity among COVID-19 research conducted in Africa, with three countries accounting for more than $80 \%$ of all registered studies. Although our results could not tell the funder of these studies, evidence showed that globally, funding of COVID-19 research is by European, Asian, and American institutions [14]. A study-not related to COVID-19 research-has highlighted the limited local funding for research in Africa, with three countries: Egypt, South Africa, and Nigeria, contributing two third of the overall funding [15]. We imagine that a similar situation would 


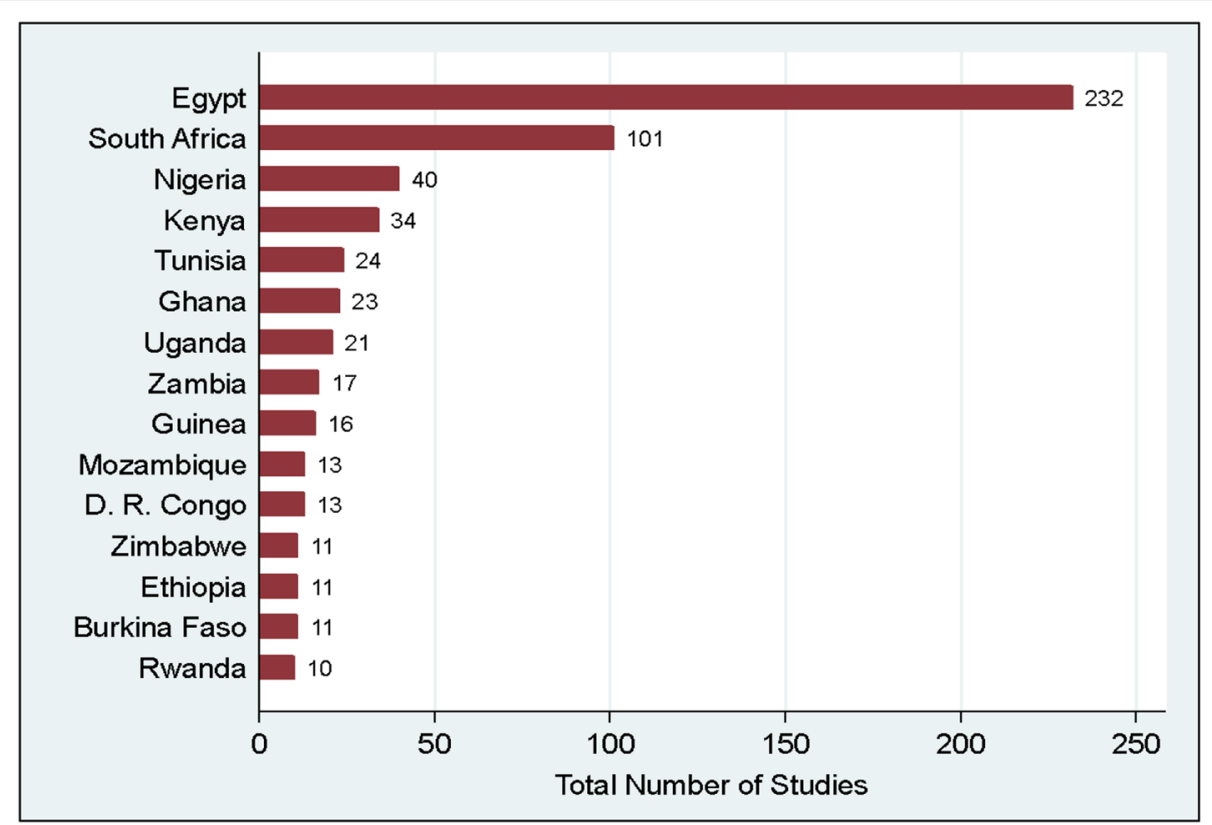

Fig. 3 Number of ongoing studies in the first fifteen African countries. *The number of studies per country reflects the number of studies conducted within that country irrespective of other sites (multicenter)

prevail for COVID-19 research; therefore, it is imperative that African countries actively seek to fund COVID19 research and other research priorities to drive their research agenda and take ownership.

The majority of the registered studies were registered prospectively, implying high compliance with WHO and ICJME regulations on clinical trial registration [8].
However, this requirement is only applicable to clinical trials and not observational studies. We cannot discern if the prospective/retrospective clinical trial registration field was completed for only clinical trials using the available data.

The epidemiology of COVID-19 is still unraveling, with highlighted knowledge gaps that need to be filled

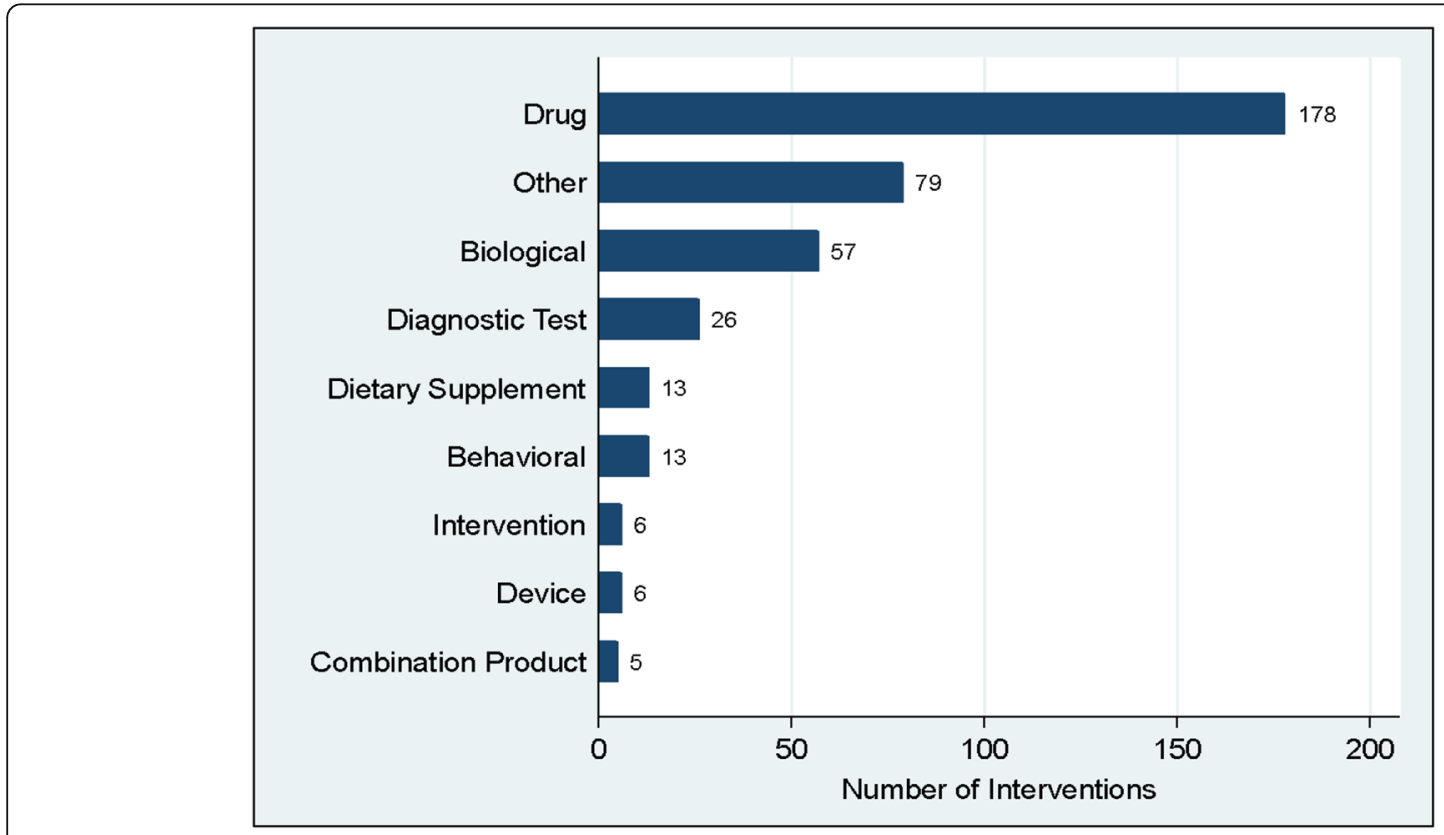

Fig. 4 Types of COVID-19 research interventions in Africa 
with evidence from robust research [12, 16]. This is more pertinent with the emergence of new strains of the SARS-COV2, such as the delta variant that has implications for effective control of the pandemic [17].

Targeted vaccination of at-risk persons against COVID-19 is ongoing in several African countries. These vaccines were granted conditional approval [18, 19] based on clinical trial data mainly not generated from the African population. Therefore, additional research is needed to monitor their safety and efficacy in this population and ensure they continually maintain a favorable risk-benefit profile. Specifically, targeted phase 4 studies will generate data to support a favorable risk-benefit balance of these interventions.

Phases 4 studies of COVID-19 vaccines would have several benefits. On the one hand, such post-licensure studies will ensure that interventions are recommended based on the best available evidence. On the other hand, the public is reassured, which may improve the uptake of vaccination and other interventions. Similarly, well-conducted observational studies will be needed to understand the drivers and predictors of the disease.

\section{Limitations of this study}

Our study has some limitations. First, we relied on studies available in the ICTRP. While this presents complete data on studies registered considering partner registers that are part of the WHO ICTRP, some studies may have been registered in non-partner registers and therefore omitted from our analysis. Furthermore, we noted that the studies in several primary registries were incomplete or missing certain variables, thus limiting our analysis and potentially biasing our results. Secondly, there is no legal/ethical requirement for prospective registration of observational studies, unlike clinical trials; therefore, we believe that the actual number of observational studies conducted in Africa may be higher than what we found in the ICTRP. Similarly, several studies have demonstrated that many studies are not in compliance with the mandated prospective registration of clinical trials, only registering these studies retrospectively, usually before disseminating the study findings in a peer-reviewed journal. Therefore, we may have missed out on some studies that have not been retrospectively registered in our analysis in this context. Finally, data on the various studies analyzed in this manuscript are from varying clinical trial registers that may have varying data completeness levels, thus affecting our ability to analyze the study findings.

Nevertheless, we provide evidence from a standard repository of clinical trials that provides a landscape of COVID-19 research conducted in Africa to help policymakers and the research community decide future research priorities.

\section{Recommendation and conclusion}

Our study highlights some crucial points. We demonstrate that research on COVID-19 is relatively skewed towards the global north, with only a small proportion of studies conducted in Africa. However, taken together with the rather impressive flurry of global research on the subject, it becomes difficult to declare the number of studies conducted in Africa as being inadequate. We also highlight the varied research areas that have been explored during the COVID-19 pandemic, both regionally and globally. Furthermore, we stress the importance of local leadership of COVID-19 research while leveraging on existing north-south collaboration.

\section{Acknowledgements \\ N/A}

Authors' contributions

BE and WW conceived the idea for the study, analyzed data, developed the first draft, and critically reviewed all drafts of the manuscript. WW and CO obtained, analyzed, and organized the data and contributed to the first draft of the paper. $\mathrm{AU}$ and $\mathrm{MC}$ participated in obtaining, organizing, analyzing, and interpreting data, and critically reviewing the manuscript's final draft.

The authors read and approved the final draft of the manuscript.

\section{Funding}

This research work did not benefit from any external funds. At the time of conducting the research, the authors were employees of their respective affiliated institutions and received a salary. The affiliated organizations were not involved in the conceptualization, conduct, analysis, or decision to publish this work.

Availability of data and materials

The data used in this study is publicly accessible from the ICTRP portal.

\section{Declarations}

Ethics approval and consent to participate

No patient-level data used in this study; therefore, ethics approval was neither required nor sought.

Consent for publication

N/A

\section{Competing interests}

The authors declare no competing interests.

\section{Author details}

${ }^{1}$ Vaccines and Immunity Theme, MRC Unit the Gambia at the London School of Hygiene and Tropical Medicine, Fajara, Gambia. ${ }^{2}$ Unit of Epidemiology and Biostatistics, School of Public Health, Faculty of Health Sciences, University of the Witwatersrand, Johannesburg, South Africa. ${ }^{3}$ Barcelona Institute for Global Health (ISGlobal), Barcelona, Spain. ${ }^{4}$ University Research Co., LLC, Manila, Philippines.

Received: 6 April 2021 Accepted: 13 September 2021

Published online: 07 October 2021

\section{References}

1. Guan W, Ni Z, Hu Y, Liang W, Ou C, He J, et al. Clinical characteristics of coronavirus disease 2019 in China. N Engl J Med. 2020;382(18):1708-20. https://doi.org/10.1056/NEJMoa2002032. 
2. Mehta HB, Ehrhardt S, Moore TJ, Segal JB. Alexander GC. Characteristics of registered clinical trials assessing treatments for COVD-19: a cross-sectional analysis. BMJ Open. 2020;10(6):e039978 [cited 2021 Jan 18] Available from: httpj//bmjopen.bmj.com/.

3. Juul S, Nielsen EE, Feinberg J, Siddiqui F, Jørgensen CK, Barot E, et al. Interventions for treatment of COVID-19: a living systematic review with meta-analyses and trial sequential analyses (The LIVING Project). PLoS Med. 2020;17(9):1-25. https://doi.org/10.1371/journal.pmed.1003293.

4. Hemkens LG, Janiaud P, Axfors C, van't Hooft J, Saccilotto R, Agarwal A, et al. The worldwide clinical trial research response to the COVID-19 pandemic - the first 100 days. F1000Research. 2020;9:1-19.

5. Edem B, Onwuchekwa C, Wariri O, Nkereuwem E, Nkereuwem OO, Williams V. Trends in clinical trial registration in sub-Saharan Africa between 2010 and 2020: a cross-sectional review of three clinical trial registries. Trials. 2021;22(1):111. Available from: https://doi.org/https://doi.org/10.1186/s13063-021-05423-1

6. Viergever RF, Li K. Trends in global clinical trial registration: an analysis of numbers of registered clinical trials in different parts of the world from 2004 to 2013. BMJ Open. 2015;5(9):6-7.

7. World Health Organization. International Clinical Trials Registry Platform (ICTRP) | primary registries [Internet]. WHO. World Health Organization; 2020 [cited 2020 Oct 18]. Available from: http://www.who.int/ictrp/network/primary/en/

8. International Committee of Medical Journal Editors. Clinical trials registration [Internet]. ICMJE. 2020 [cited 2020 May 21]. Available from: http://www. icmje.org/about-icmje/faqs/clinical-trials-registration/

9. Williams RJ, Tse T, Harlan WR, Zarin DA. Registration of observational studies: is it time? CMAJ. 2010;182(15):1638-42 [cited 2021 Apr 2] Available from: /pmc/articles/PMC2952011/.

10. Chavers S, Fife D, Wacholtz M, Stang P, Berlin J. Registration of observational studies: perspectives from an industry-based epidemiology group. Pharmacoepidemiol Drug Saf. 2011;20(10):1009-1013. [cited 2021 Apr 3] Available from: https://onlinelibrary-wiley-com.ez.lshtm.ac.uk/doi/epdf/ https://doi.org/10.1002/pds.2221

11. Boccia S, Rothman K, Panic N, Flacco ME, Rosso A, Pastorino R, et al. Registration practices for observational studies on ClinicalTrials.gov indicated low adherence. J Clin Epidemiol. 2016;70:176-82 [cited 2021 Apr 3] Available from: https://www-sciencedirect-com.ez.lshtm.ac.uk/science/a rticle/pii/S0895435615004321.

12. Osuchowski MF, Aletti F, Cavaillon JM, Flohé SB, Giamarellos-Bourboulis EJ, Huber-Lang M, et al. SARS-CoV-2/COVID-19: evolving reality, global response, knowledge gaps, and opportunities. Shock. 2020;54(4):416-37 [cited 2021 Jan 19] Available from: https://pubmed.ncbin.nlm.nih. gov/32433217/.

13. World Health Organization. A COORDINATED GLOBAL RESEARCH ROADMAP: 2019 NOVEL CORONAVIRUS [Internet]. Geneva; 2020 Mar [cited 2021 Jan 18]. Available from: https://www.glopid-r.org/wp-content/uploa ds/2020/03/who-2019-novel-coronavirus-global-research-roadmap.pdf

14. UK Collaborative on Development Research(UKCDR) \& Global Research Collaboration for Infectious Disease Preparedness (GloPID-R). COVID-19 research project tracker [Internet]. 2020 [cited 2021 Aug 17]. Available from: https://www.ukcdr.org.uk/covid-circle/covid-19-research-project-tracker/

15. Simpkin V, Namubiru-Mwaura E, Clarke L, Mossialos E. Investing in health R\&D: where we are, what limits us, and how to make progress in Africa analysis. BMJ Glob Heal. 2019;4:1047 Available from: http://gh.bmj.com/.

16. Idele P, Anthony D, You D, Luo C, Mofenson L. The evolving picture of SARS-COV-2 and COVID-19 in children: critical knowledge gaps. BMJ Glob Heal. 2020;5(9):e003454 [cited 2021 Jan 19] Available from: https://gh.bmj. com/content/5/9/e003454.

17. Karim SSA, de Oliveira T. New SARS-CoV-2 variants-clinical, public health, and vaccine implications. N Engl J Med. 2021;384(19):1866-8 [cited 2021 Aug 17] Available from:/pmc/articles/PMC8008749/.

18. World Health Organization. WHO issues its first emergency use validation for a COVID-19 vaccine and emphasizes need for equitable global access [Internet]. 2020 [cited 2021 Jan 19]. Available from: https://www.who.int/ news/item/31-12-2020-who-issues-its-first-emergency-use-validation-for-acovid-19-vaccine-and-emphasizes-need-for-equitable-global-access

19. Krause PR, Gruber MF. Emergency Use Authorization of COVID vaccines - safety and efficacy follow-up considerations. N Engl J Med. 2020;383(19):e107 [cited 2021 Aug 17] Available from: https://pubmed.ncbi.nlm.nih.gov/33064383/.

\section{Publisher's Note}

Springer Nature remains neutral with regard to jurisdictional claims in published maps and institutional affiliations.

\section{Ready to submit your research? Choose BMC and benefit from}

- fast, convenient online submission

- thorough peer review by experienced researchers in your field

- rapid publication on acceptance

- support for research data, including large and complex data types

- gold Open Access which fosters wider collaboration and increased citations

- maximum visibility for your research: over $100 \mathrm{M}$ website views per year

At BMC, research is always in progress.

Learn more biomedcentral.com/submissions 